\title{
Three Phase Four Wire Shunt Active Power Filter from Theory to Industrial Facility Tests
}

\author{
Bruno Exposto, Henrique Gonçalves, J. G. Pinto, João L. Afonso, Carlos Couto \\ Centro Algoritmi - Departamento de Electrónica Industrial \\ Univ. Minho - Campus de Azurém 4800-058 - Guimarães, Portugal \\ Phone:+351 253510190 \\ E-mail: bexposto@dei.uminho.pt,hgoncalves@dei.uminho.pt, gpinto@dei.uminho.jla@dei.uminho.pt,ccouto@dei.uminho.pt
}

\begin{abstract}
Non-linear loads are very common in present industrial facilities, office buildings and even in our homes. This loads present several Power Quality problems to the electrical grid. The conventional solutions do not solve these problems in a suitable way. Therefore, it is necessary to find new solutions such as Active Power Filters. This paper presents and discusses the main steps that are necessary to implement a Three Phase Four Wire Shunt Active Power Filter from theory to field tests. Therefore it is a contribution on several topics. Starting with the main control theories used on this topology, it explains the $p-q$ Theory in a more detailed way. It also gives a brief presentation of some modulation techniques. There are presented computational simulation results and field tests results of the developed filter operating in an industrial facility.
\end{abstract}

Keywords: Shunt Active Filter; p-q Theory; PeriodicSampling;

\section{INTRODUCTION}

Non-linear loads are commonly present in industrial facilities, office buildings and even in our homes. They present several Power Quality problems to the electrical grid and can introduce economic wastes derived from the malfunction or even because of the destruction of electrical equipments. Other important aspect of several loads is the consumption of reactive power, introducing low power factor and increasing the installation electrical losses.

The conventional solutions, such as tuned passive filters for current harmonics and capacitor banks for power factor correction, do not solve these problems in a suitable way. Many times these solutions can cause other problems, such as resonances. Therefore, it is necessary to find new solutions to these problems. Shunt Active Power Filters are a more effective alternative than the conventional solutions. They allow the dynamic compensation of current harmonics, power factor and unbalances correction, without causing the problems that the passive filters and capacitor banks can cause.

This paper presents simulation results and field test results of a three-phase, four wire Shunt Active Power Filter operating in an industrial facility. It presents and discusses the main steps that are necessary to implement a Shunt Active Power Filter, beginning with the control theories, passing through the modulation techniques and finalizing with a comparison between simulation and field tests results. It is a contribution on several topics. First contributes for an easy understanding of Shunt Active Power Filters, secondly gives some design details, and finally presentation of field results which allows validating the simulation models.

\section{CONTROL SCHEME}

\section{A. $P-Q$ Theory}

The control of the developed Shunt Active Power Filter relies in the $p-q$ Theory proposed by Akagi et al. [1], with the "Sinusoidal Source Currents" algorithm implemented. To use this control, it was necessary to implement a Phase-Lock Loop Circuit (PLL) that extracts the positive sequence values of the source voltages. Although it has been used a PLL circuit in this case, there are other several methods to perform this task. Methods like band-pass filter [2] or a low-pass filter [3], are also a solution to obtain the positive sequence values of the source voltages can also be used. After obtain the positive sequence values of the source voltages is applied to them and to the load currents $i_{a}, i_{b}, i_{c}$ the $\alpha-\beta-0$ transformation, (2) and (1) respectively.

$$
\begin{aligned}
& {\left[\begin{array}{c}
i_{0} \\
i_{\alpha} \\
i_{\beta}
\end{array}\right]=\sqrt{2 / 3} \cdot\left[\begin{array}{ccc}
1 / \sqrt{2} & 1 / \sqrt{2} & 1 / \sqrt{2} \\
1 & -1 / 2 & -1 / 2 \\
0 & \sqrt{3} / 2 & -\sqrt{3} / 2
\end{array}\right] \cdot\left[\begin{array}{c}
i_{a} \\
i_{b} \\
i_{c}
\end{array}\right]} \\
& {\left[\begin{array}{c}
v_{0} \\
v_{\alpha} \\
v_{\beta}
\end{array}\right]=\sqrt{2 / 3} \cdot\left[\begin{array}{ccc}
1 / \sqrt{2} & 1 / \sqrt{2} & 1 / \sqrt{2} \\
1 & -1 / 2 & -1 / 2 \\
0 & \sqrt{3} / 2 & -\sqrt{3} / 2
\end{array}\right] \cdot\left[\begin{array}{c}
v_{a} \\
v_{b} \\
v_{c}
\end{array}\right]}
\end{aligned}
$$

Then the instantaneous real power, $p$, the instantaneous imaginary power, $q$, and the instantaneous zero-sequence power, $p_{0}$, are calculated in the new reference frame (3).

$$
\left[\begin{array}{c}
p_{0} \\
p \\
q
\end{array}\right]=\left[\begin{array}{ccc}
v_{0} & 0 & 0 \\
0 & v_{\alpha} & v_{\beta} \\
0 & -v_{\beta} & v_{\alpha}
\end{array}\right] \cdot\left[\begin{array}{c}
i_{0} \\
i_{\alpha} \\
i_{\beta}
\end{array}\right]
$$


Through a sliding window average algorithm, it is obtained the value of the instantaneous real power $(\vec{p})$ Using the value of $\bar{p}$ and $\mathrm{p}$ is calculated the alternating part of the real power, $\tilde{p}$, and the mean value of the instantaneous zero-sequence power, $\overline{p_{0}}$ These values and $p_{\text {reg, }}$, which corresponds to the DC link voltage regulation, instantaneous active power, are used to calculate $p_{x}$ and $q_{x}$ (4) (5)

$$
\begin{gathered}
p_{x}=\tilde{p}-\bar{p}_{0}-p_{\text {reg }} \\
q_{x}=q
\end{gathered}
$$

Using $p_{x}$ and $q_{x}$ it is possible to determine the $\alpha-\beta-0$ reference currents that should be generated by the Active Filter inverter (6) (7).

$$
\begin{gathered}
{\left[\begin{array}{l}
i_{c \alpha} \\
i_{c \beta}
\end{array}\right]=\frac{1}{v_{\alpha}^{2}+v_{\beta}^{2}} \cdot\left[\begin{array}{cc}
v_{\alpha} & -v_{\beta} \\
v_{\beta} & v_{\alpha}
\end{array}\right] \cdot\left[\begin{array}{l}
p_{x} \\
q_{x}
\end{array}\right]} \\
{ }_{c 0}=i_{0}
\end{gathered}
$$

The compensating reference currents $i_{c \alpha}$ and $i_{c \beta}$ are then converted to the $a-b-c$ coordinates system and the reference compensating currents $\left(i_{c a}, i_{c b}, i_{c c}, i_{c n}\right)$ are then determined using (8) and (9).

$$
\begin{gathered}
{\left[\begin{array}{c}
i_{c a} \\
i_{c b} \\
i_{c c}
\end{array}\right]=\sqrt{2 / 3} \cdot\left[\begin{array}{ccc}
1 / \sqrt{2} & 1 & 0 \\
1 / \sqrt{2} & -1 / 2 & \sqrt{3} / 2 \\
1 / \sqrt{2} & -1 / 2 & -\sqrt{3} / 2
\end{array}\right] \cdot\left[\begin{array}{c}
{ }^{{ }_{c}}{ }^{c 0} \\
{ }_{c}{ }_{c \alpha} \\
i_{c \beta}
\end{array}\right]} \\
i_{c n}=-\left(i_{c a}+i_{c b}+i_{c c}\right)
\end{gathered}
$$

Although that $p-q$ Theory is a good solution to determine the current components that must be compensated, there are several other current reference generation strategies based on frequency-domain or time-domain. The frequency domain strategies involve the Fourier transform calculations to obtain the compensations reference harmonics currents [4]. The time-domain control strategies usually involve power theories. In this area besides the $p-q$ Theory it can be used the FBD (Fryze - Buchholz - Depenbrock) Theory [5] or Conservative Power Theory, CPT [6]. Each one of these solutions has advantages and drawbacks, which must be evaluated according to the electrical system characteristics and the final results that one wants obtain.

\section{B. DC Link Voltage Regulation}

The DC link capacitor voltage must be correctly controlled so that the Active Filter performance doesn't be compromised. An incorrect DC link capacitor voltage regulation could lead to undesired harmonics in the compensation currents.

In this case, the DC link capacitor voltage is controlled by a Proportional (P) controller that generates a $p_{\text {reg }}$ signal which is proportional to the error between the DC link reference voltage and the measured value of the DC link voltage (6). The $p_{\text {reg }}$ signal is then introduced in the $p-q$ Theory calculations as seen in (4). This allows to regulate the DC link capacitor while maintaining the system currents sinusoidal and in phase with the voltages.

$$
p_{r e g}=\left(v_{d c_{-} r e f}-v_{d c}\right) \cdot K_{p}
$$

The DC link capacitor voltage can also be regulated using instead of a proportional controller, a proportional-integral (PI) controller.

\section{ACTIVE POWER FILTER TOPOLOGY}

The implemented Active Filter topology (Fig.1) is composed by a three-phase four wire voltage-source inverter. The neutral wire is connected toa an IGBT arm, as all the phase wires. The inverter has one $4500 \mu \mathrm{F}$ capacitor in the DC side and is shunt connected with the electrical grid through four $3.5 \mathrm{mH}$ inductors.

The passive filters are an important part of the Active Filter. They must be dimensioned so that the switching frequency doesn't affect the source currents THD after the compensation. Careful design must be taken to also prevent the interference of the passive filters with the control of the Active Filter.

In this paper is presented an Active Filter where has been used only an inductor has passive filter, but the passive filter configuration can be a $L C$ or $L C R$, or even more complex topologies. Each one of these topologies has advantages and drawbacks, which must be weighted according with the type of loads that will be compensated, the IGBT switching frequency, the control of the Active Filter and the final cost.

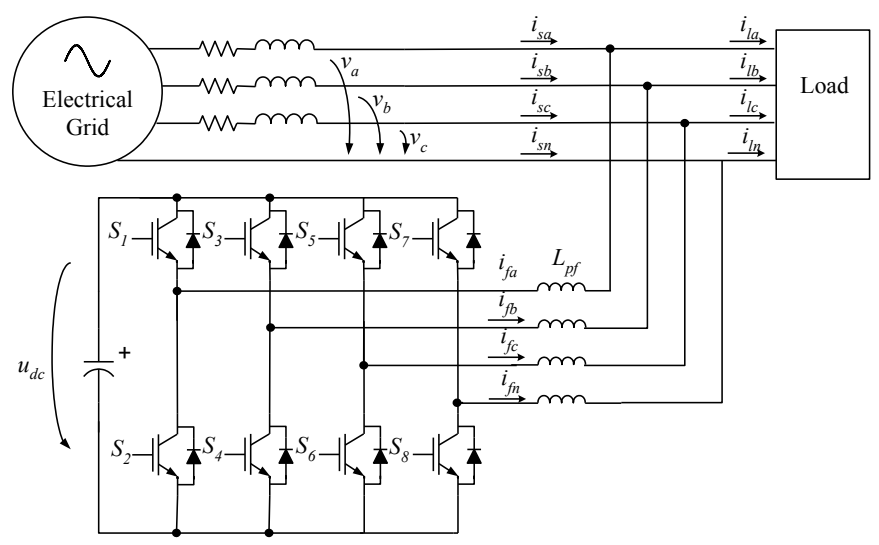

Fig.1 Implemented Shunt Active Power Filter 


\section{CURRENT CONTROL AND MODULATION TECHNIQUES}

The modulation technique used in simulations and implementation of the Active Power Filter was Periodic Sampling. This is a simple modulation technique that does not work with a fixed switching frequency [7] it only establishes an upper frequency limit. The control of the synthetized currents is done comparing the reference current $\left(i_{c x}\right)$ with the current produced by the inverter $\left(i_{f x}\right)$.the result of that comparison is sent to a D type flip-flop (Fig.2).

There are other modulation schemes that have been successfully applied to Shunt Active Filters, namely: carrierbased pulse width modulation, hysteresis band modulation, and space-vector modulation [7].

Carrier-based pulse width modulation (CB-PWM) is a modulation technique that is implemented comparing the current reference signal $\left(i_{c x}\right)$ with a triangular carrier [8]. The IGBTs are then actuated accordingly with that comparison (Fig.3). The switching frequency is defined in this case by the triangular carrier frequency.

Other modulation technique that can be used in Shunt Active Power Filters is hysteresis band modulation technique. In this case the reference current $\left(i_{c x}\right)$ is compared with the synthetized current $\left(i_{f x}\right)$. The IGBTs are switched when the error of the comparison exceeds a hysteresis band (Fig.4). The most complex modulation technique used in Active Power Filters is space-vector modulation. This modulation technique requires that the reference currents $\left(i_{c a}, i_{c b}, i_{c c}\right)$ and the inverter currents be converted to a $\alpha-\beta$ reference frame. The inverter IGBT switching state vectors are defined according to the position of the current reference vectors in this reference frame.

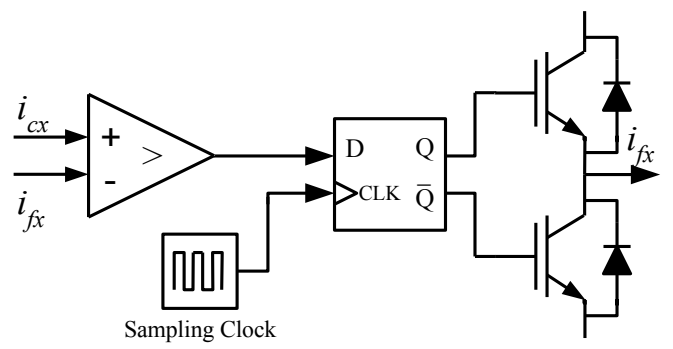

Fig.2 Periodic sampling modulation technique implementation model

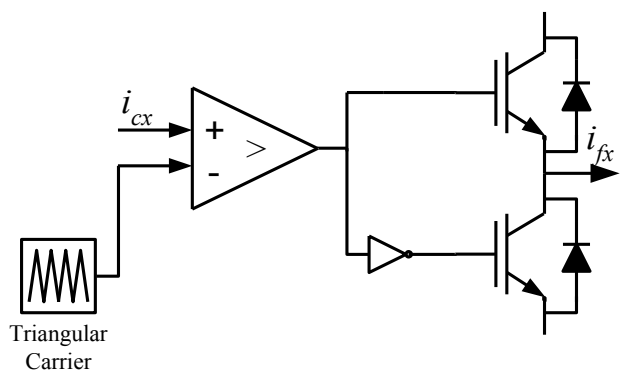

Fig.3 Carrier-based pulse width modulation technique implementation model

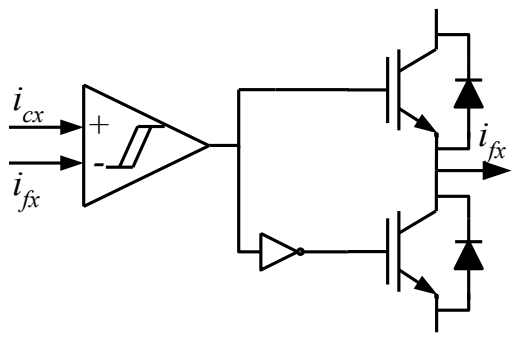

Fig.4 Hysteresis band modulation technique implementation model

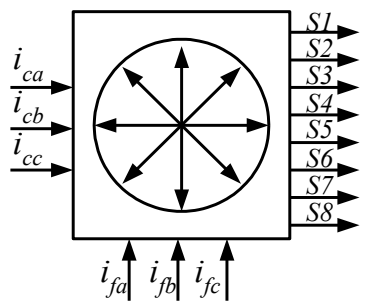

Fig.5 Space-vector modulation technique implementation model

\section{ACTIVE POWER FILTER SimUlations MODELS}

Before the implementation of the Shunt Active Power Filter it was developed a simulation model using PSIM software. With PSIM it is possible to simulate in the same model the hardware and the control. PSIM supports blocks that allow users to use $\mathrm{C}$ code. This feature has two main advantages. First it allows testing the performance of the control scheme in a way much closer to the final control that will be implemented in the DSP. Second with the minimum effort, the $\mathrm{C}$ code used in the simulation can be easily translated to the DSP code and some implemented functions can even be used directly in the DSP.

In order to guarantee an accurate simulation model, the main hardware characteristics of the Active Filter and loads were modeled. Also, the signals that will be measured by the ADCs, were simulated using variables with the same bits resolution that the real ones. It was intended to test the three phase Shunt Active Power Filter in an industrial environment. In order to predict the behavior of the Active Filter in the field tests, the industrial testing facility electrical installation was monitored, to assess the electrical profile.

\section{Simulation Results}

In the industrial facility, a textile industry, the loads are an industrial textile machine and several mechanisms with variable speed drives. The load currents have high distortion levels (Fig. 6), confirming that the loads are mainly nonlinear loads. The neutral currents are very low, indicating that the loads are balanced. 


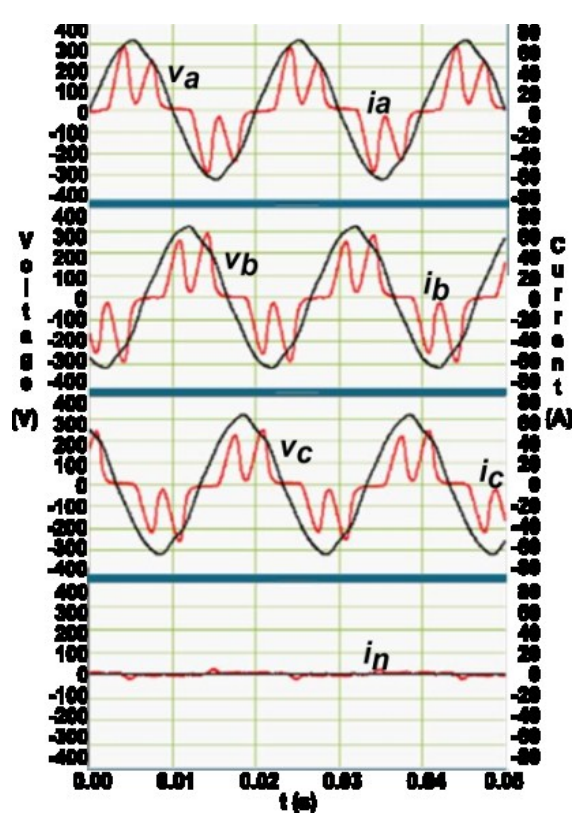

Fig. 6 Textile industry electrical system voltages and currents

In Fig. 7 are presented the simulated load currents. The figure shows that the current waveforms are similar to the ones measured in the textile industry. The currents are highly distorted and the voltages are practically sinusoidal. The loads are balanced, so there is almost no neutral current present in the electrical installation.

After the compensation the source currents $\left(i_{s a}, i_{s b}, i_{s c}\right)$ assume a nearly sinusoidal form and are in phase with the systems voltages (Fig. 8). The neutral current $\left(i_{s n}\right)$ is very low, as before the compensation. This indicates that the compensation is being correctly done. The simulated Active Filter performs well with this type of load connected to the electrical grid.

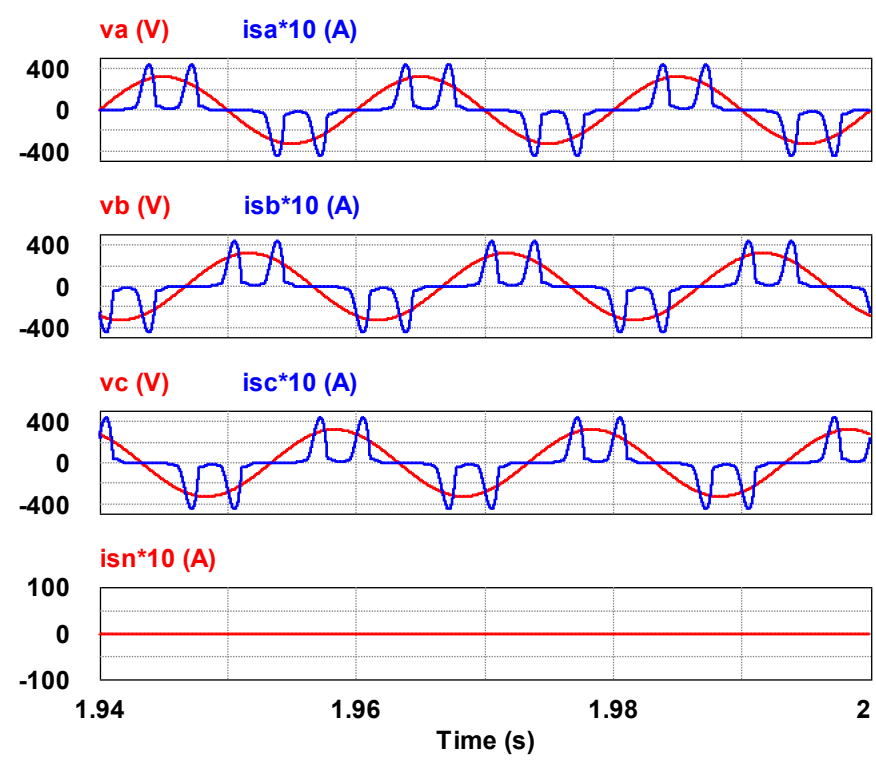

Fig.7 Simulated textile industry, electrical system voltages $\left(v_{a}, v_{b}, v_{c}\right)$ and currents $\left(i_{s a}, i_{s b}, i_{s c}, i_{s n}\right)$,without compensation

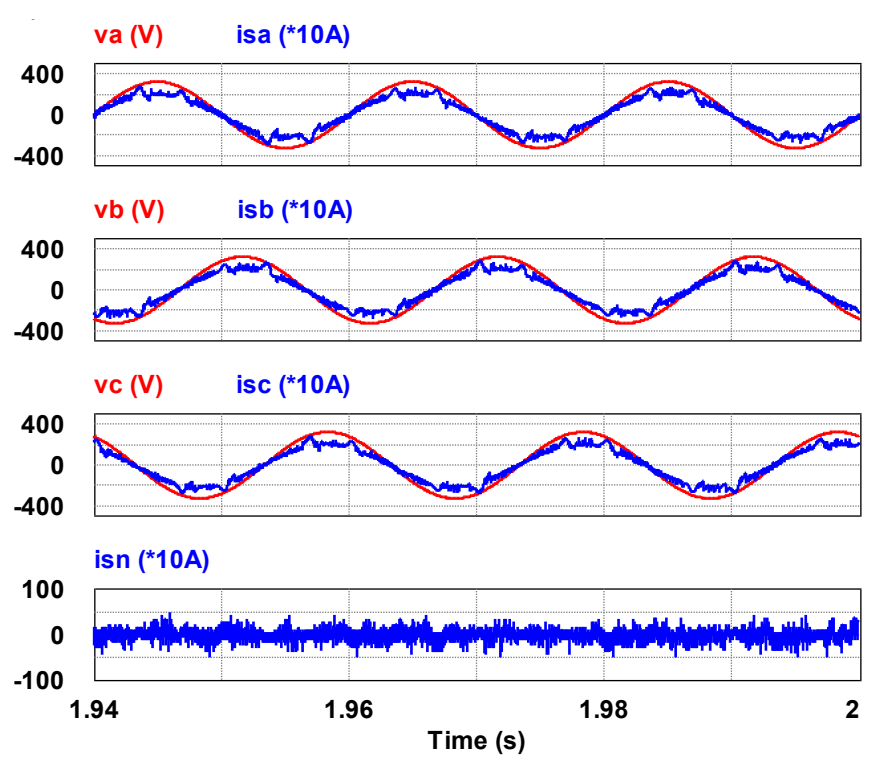

Fig. 8 Simulated textile industry, electrical system voltages (va, vb, vc) and currents (isa, isb, isc, isn), after compensation

As can be seen in Fig. 9 the inverter currents $\left(i_{f a}, i_{f b}, i_{f c}\right)$ are very similar to the reference currents $\left(i_{c a}, i_{c b}, i_{c c}, i_{c n}\right)$. This indicates that the inverter can properly synthetize the currents that are required to compensate the distorted currents absorbed by the load.

The DC link capacitor voltage presents a ripple (Fig.10). This ripple is due to the fact that the Active Filter is compensating a non-linear load. Nevertheless, the DC link voltage control performs well, and the voltage ripple never exceeds $15 \mathrm{~V}$.

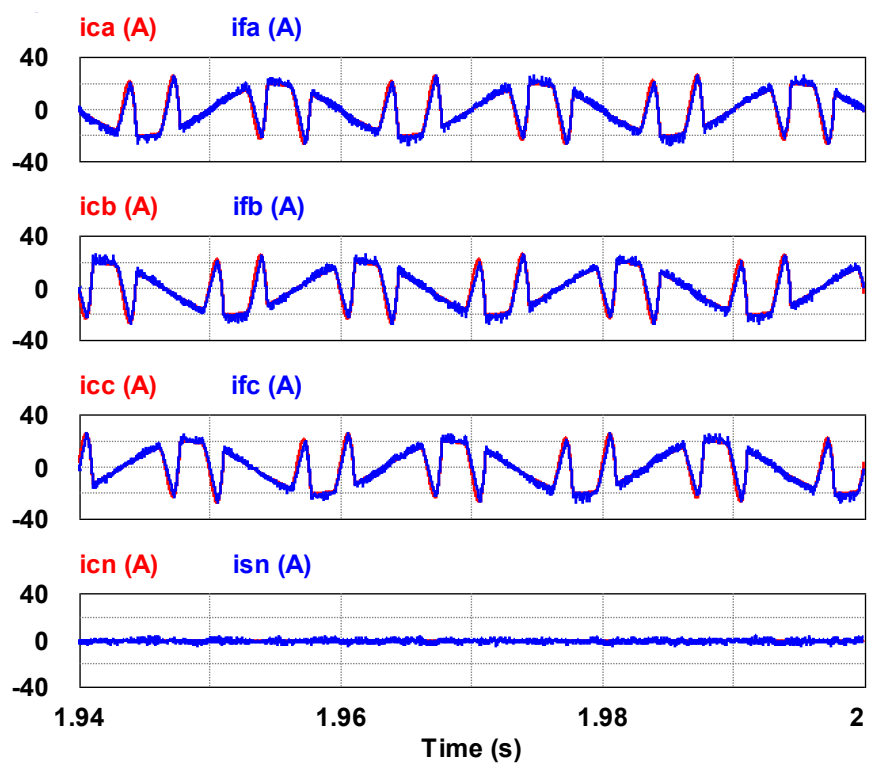

Fig.9 Simulated reference currents $\left(i_{c a}, i_{c b}, i_{c c}\right)$ and synthetized currents $\left(i_{f a}\right.$, $\left.i_{f b}, i_{f c}, i_{f n}\right)$, without compensation 


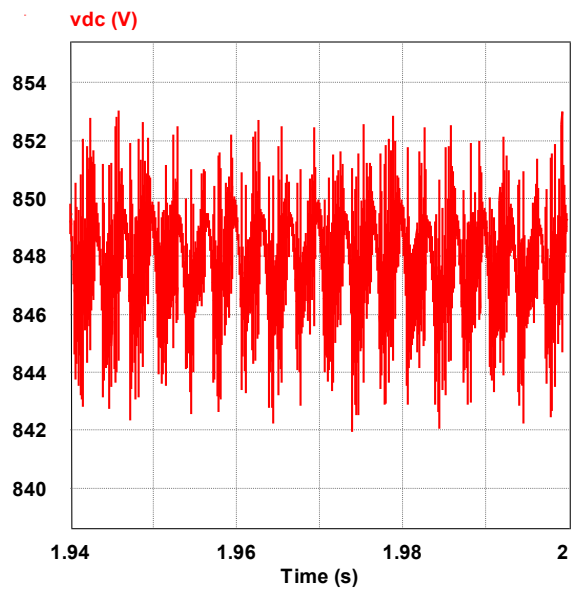

Fig.10 DC link capacitor voltage waveform during compensation

\section{HARDWARE DESCRIPTION}

The inverter topology of the Active Filter is a four arms two level voltage source inverter similar to the one in Fig.1. The inverter is connected to the grid using output filtering inductors. The voltage and current sensors are Hall Effect sensors. The control of the developed Active Power Filter was implemented in a Texas Instruments DSP TMS320F2812.

The implemented Active Filter has also several hardware and software protection mechanisms, namely, DC link capacitor overvoltage protection, short circuit and overcurrent protection and temperature protection. All these protection mechanisms are software and hardware protection schemes. In case of failure they disable the Active Filter and disconnect it from the electrical grid.

\section{EXPERIMENTAL FIELD RESULTS}

The field results show that the implemented Active Filter is capable of compensate distorted currents absorbed by the electrical installation loads. As Fig.11 show, the source currents after the compensation are sinusoidal and in phase with the system voltages. This indicates that the Active Filter is properly compensating the load current harmonics. The neutral current remains nearly zero after the compensation.

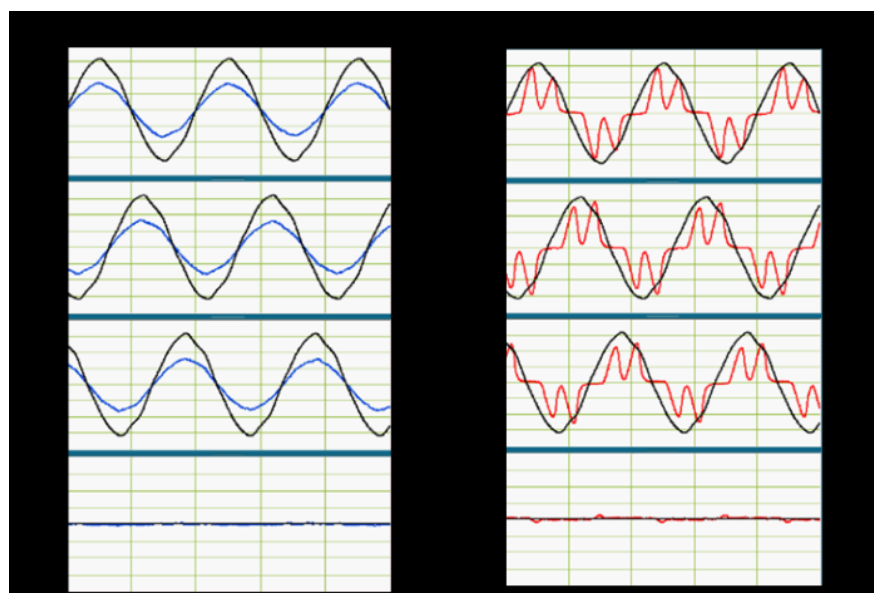

Fig.11 Textile industry, electrical system voltages and currents, in source and load, with compensation

\section{CONCLUSION}

This paper presented the design steps and some implementation details of a Three Phase Four Wire Shunt Active Power Filter with a digital control system based on the $p-q$ Theory. It also presented the simulated results and experimental field tests results in an industrial facility. During the explanation of the design steps, are referred different control theories, passive filter topologies, modulation and current control techniques.

The performance of the Active Filter was very satisfactory and the comparison between the experimental and the simulated results attests the accuracy of the simulation model developed for the Three Phase Four Wire Shunt Active Filter.

\section{ACKNOWLEDGMENT}

This work is financed by FEDER Funds, through the Operational Programme for Competitiveness Factors COMPETE, and by National Funds through FCT Foundation for Science and Technology of Portugal, under the project PTDC/EEA-EEL/104569/2008.

\section{REFERENCES}

[1] H. Akagi, Y. Kanazawa, A. Xabae, "Generalized Theory of the Instantaneous Reactive Power in Three-phase Circuits",IPEC'83 - Int. Power Electronics Conference; Tokyo, Japan; 1983; pp. 1375-1386.

[2] Karimi, S.; Poure, P.; Saadate, S., "Reference current generation without PLL for shunt active filter under distorted and unbalanced conditions", Industrial Electronics, 2008. ISIE 2008. IEEE International Symposium onIndustrial Electronics, vol., no., pp.363-368, June 30 2008-July 2, 2008.

[3] Scherer, L.; de Camargo, R.F.; de Campos, M.; Silva, G.S.; Feyh, A. "Synchronization methods applied on active power filters - A comparative study," Industry Applications (INDUSCON), 2010 9th IEEE/IAS International Conference on , vol., no., pp.1-6, 8-10 Nov. 2010 .

[4] W. M. Grady, M. J. Samotyj, and A. H. Noyola, "Survey of active power line conditioning methodologies", IEEE Trans. Power Delivery, vol. 5, pp. 1536-1542, 1990.

[5] Staudt, V., "Fryze - Buchholz - Depenbrock: A time-domain power theory, "Nonsinusoidal Currents and Compensation", 2008. ISNCC 2008. International School on, vol., no., pp.1-12, 10-13 June 2008

[6] P. Tenti, P. Mattavelli, A time-domain approach to power term definitions under non-sinusoidal conditions, 6th International Workshop on Power Def and Meas under Non-sinusoidal Conditions, IEEE Instrum and Meas Society, North Italy Chapter, Milano, Italy, 2003, pp. 41-50.

[7] S. Buso; L. Malesani; P. Mattavelli; "Comparison of Current Control Techniques for Active Filter Applications", IEEE Transactions on Industrial Electronics, vol. 45, Issue 5, Oct. 1998; Page(s):722 - 729.

[8] Pregitzer, R. Pinto, J.G. Monteiro, L.F.C. Afonso, J.L., "Shunt Active Power Filter with Dynamic Output Current Limitation", ISIE'2007 IEEE Symposium on Industrial Electronics, Vigo, Spain, 4-7 July 2007. 